\title{
Preparation and In-vitro Characterization of Gastroretentive Floating Tablets of Domperidone
}

\author{
Ikramul Hasan, Tushar Saha and Md. Selim Reza \\ Department of Pharmaceutical Technology, Faculty of Pharmacy, University of Dhaka \\ Dhaka-1000, Bangladesh
}

(Received: February 2, 2019; Accepted: March 10, 2019; Published: July 22, 2019)

\begin{abstract}
The present investigation was design for domperidone floating table preparation and in-vitro characterization. The ultimate target was increasing gastric retention by means of floatability of the tablet. Hydrophilic cellulosic polymers, Methocel K15M and Methocel K100M were used in this experiment for achieving release controlling property. Sodium bicarbonate played the key role of floatation by generating gas. Direct compression was the method of choice for preparing the tablets. The tablets were evaluated for physical parameters, buoyancy study, total floating time determination and dissolution study. Acidic dissolution medium $(0.1 \mathrm{~N} \mathrm{HCl})$, mimicking the environment of the stomach, was used in USP II apparatus for 12 hours to find out the pattern of drug release. The release mechanism was analyzed by exploring the zero order, first order, Higuchi and Korsmeyer equations. All the physical parameters were within acceptable range and Methocel K100M showed more floating lag time and sustained release property than Methocel K15M. All the formulations showed more than 12 hours floating time. Fourier Transform Infrared Spectroscopy (FTIR) study confirmed the compatibility of the drug with the excipients.
\end{abstract}

Key words: Gastric retention, hydrophilic cellulose derivatives, domperidone.

\section{Introduction}

For the last couple of decades oral sustained release dosage forms is attracting the attention of pharmaceutical researchers because of their significant benefits (Hoffman, 1998). But, because of being stomach as the principal absorption site, many important drug candidates are not suitable for this approach. As the travel time in the stomach is very short, this dosage forms lefts the stomach quickly and released in the non-absorbing part. The consequence is lower bioavailability of the drug (Tushar et. al., 2018). In such cases, gastric retention of the dosage form will be a better option. This dosage form will ensure the release of drug in sustained fashion in the upper part of gastrointestinal tract (Hoffman, 1999; Hwang et. al., 1998). There are many approaches of increasing gastric retention like- floating drug delivery (Singh and Kim, 2000), mucoadhesion (Moes, 1993), decresing gastric motility (Rubinstein and Friend, 1994) etc. In this study floating drug delivery system is developed and explored.

Domperidone, a benzimidazole derivative, is a popular antiemetic drug. It is indicated for nausea, vomiting, gastroparesis, gastrointestinal motility disorders (Reynolds, 1996; Albright, 2005) etc. Domperidone is degraded in the intestinal fluid and results in lower bioavailability (Thomma and Zimmer, 1990; Sheth and Tossounian, 1979).

In this study gastro retentive floating tablet of domperiodne was prepared using $\mathrm{NaHCO}_{3}$ as floating agent and Methcoel K15M, Methocel K100M as release retardant. After preparing the tablets, in-vitro characterization were done. 


\section{Materials and Methods}

Pure domperidone was a gift from ACI Pharmaceuticals Ltd. Bangladesh for research purpose. Polymers (Methocel K15M and Methocel K100M) were provided by Colorcon Ltd. Microcrystalline cellulose, sodium bi-carbonate, magnesium stearate and talc were purchased from local market.

Instrument used in the experiments included RADWAG weight machine (Model: PS210.R1), Poland, YD-1 tablet hardness tester China, EMC61PC-UV spectrophotometer (EMC Lab), Germany,
Electrolab dissolution tester (Model: ETC 11LX), India, FT-IR spectrophotometer (Shimadzu, Japan), etc.

Method of preparation of domperidone floating tablet: Direct compression was the method of choice for preparing domperidone gastro retentive floating tablets. Drug and excipients were weighed according to the table 1 and mixed for a definite period of time. After proper blending and mixing that was transferred to tablet compression machine. After direct compression the tablets were prepared.

Table 1. The composition of different gastroretentive floating domperidone (DOM) tablet formulations.

\begin{tabular}{lcccccccc}
\hline Formulation & $\begin{array}{c}\text { DOM } \\
(\mathrm{mg})\end{array}$ & $\begin{array}{c}\text { Methocel } \\
\text { K15M } \\
(\mathrm{mg})\end{array}$ & $\begin{array}{c}\text { Methocel } \\
\text { K100M } \\
(\mathrm{mg})\end{array}$ & $\begin{array}{c}\text { Microcrystalline } \\
\text { cellulose } \\
(\mathrm{mg})\end{array}$ & $\begin{array}{c}\text { Sodium } \\
\text { bi-carbonate } \\
(\mathrm{mg})\end{array}$ & $\begin{array}{c}\text { Magnesium } \\
\text { stearate } \\
(\mathrm{mg})\end{array}$ & $\begin{array}{c}\text { Talc } \\
(\mathrm{mg})\end{array}$ & $\begin{array}{c}\text { Total } \\
\text { weight } \\
(\mathrm{mg})\end{array}$ \\
\hline D-1 & 30 & 35 & - & 97 & 15 & 1 & 2 & 180 \\
D-2 & 30 & 45 & - & 87 & 15 & 1 & 2 & 180 \\
D-3 & 30 & 55 & - & 77 & 15 & 1 & 2 & 180 \\
D-4 & 30 & - & 35 & 97 & 15 & 1 & 2 & 180 \\
D-5 & 30 & - & 45 & 87 & 15 & 1 & 2 & 180 \\
D-6 & 30 & - & 55 & 77 & 15 & 1 & 2 & 180 \\
\hline
\end{tabular}

Characterization of physical properties: Official USP method was followed to determine the tablet diameter, thickness, hardness, weight variation and friability.

Buoyancy study: $100 \mathrm{ml} 0.1 \mathrm{~N} \mathrm{HCl}$ was used as the floating media. Floating duration time and lag time were measured from this in vitro buoyancy study (Khan et. al., 2009).

Dissolution study: In vitro dissolution study was conducted using USP dissolution apparatus II. Dissolution media of $\mathrm{pH} 1.2$ was used to simulate the environment of the stomach (Khan et. al., 2009). Twelve hours dissolution was conducted with data from every hour. Drug release was studied by zero order, first order, Higuchi and Korsmeyer Peppas model to get the release pattern of the drug.

Compatibility study: FTIR was used for conforming the compatibility of the formulation. Pure drug, polymers and physical mixture of drug and polymers were subjected to FTIR study.

\section{Results and Discussion}

Physical properties: Diameter, thickness, hardness, weight variation, friability of the prepared tablets were measured following the USP recommendation and all the data were within the range. The data are given in table 2 .

Buoyancy study: Floating duration time and lag time were determined for all the formulations. Formulation D-6 showed maximum lag time and formulation D-3 showed minimum lag time. The results of buoyancy study are given in table 3 and the sequence of floatation ism showed in figure 1.

Dissolution study: Drug release patterns are demonstrated in figure 2. From figure, it is clear that, formulation D-1 released almost its entire drug after 
$12 \mathrm{hrs}$ time period. On the other hand, D-2 and D-3 released $80 \%$ and $70 \%$ drug respectively after $12 \mathrm{hrs}$. In case of formulations, D-4, D-5 and D-6 the drug released were not satisfactory and it was 59\%, 55\% and 50\% respectively. The higher the amount of polymers used the release pattern became more sustained in case of Methocel K100M and it was opposite for Methocel K15M polymer.

Table 2. Physical properties of the tablets.

\begin{tabular}{cccccc}
\hline Formulation & $\begin{array}{c}\text { Average weight } \\
(\mathrm{mg})\end{array}$ & $\begin{array}{c}\text { Diameter } \\
(\mathrm{mm})\end{array}$ & $\begin{array}{c}\text { Thickness } \\
(\mathrm{mm})\end{array}$ & $\begin{array}{c}\text { Hardness } \\
\left(\mathrm{kg} / \mathrm{cm}^{2}\right)\end{array}$ & $\begin{array}{c}\text { Friability } \\
(\%)\end{array}$ \\
\hline D-1 & $177 \pm 3.21$ & & & $5.35 \pm 0.17$ & 0.17 \\
D-2 & $174 \pm 2.65$ & & & $5.48 \pm 0.23$ & 0.26 \\
D-3 & $180 \pm 4.12$ & $7.03 \pm 0.02$ & $4.05 \pm 0.01$ & $5.33 \pm 0.21$ & 0.54 \\
D-4 & $172 \pm 3.19$ & & & $5.61 \pm 0.28$ & 0.22 \\
D-5 & $178 \pm 3.11$ & & & $5.43 \pm 0.19$ & 0.66 \\
D-6 & $177 \pm 4.02$ & & & $5.46 \pm 0.34$ & 0.29 \\
\hline
\end{tabular}

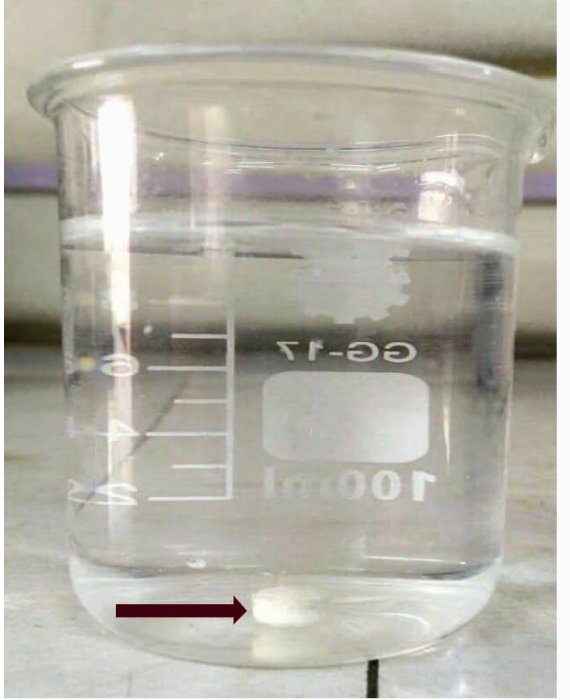

(A) At initial stage

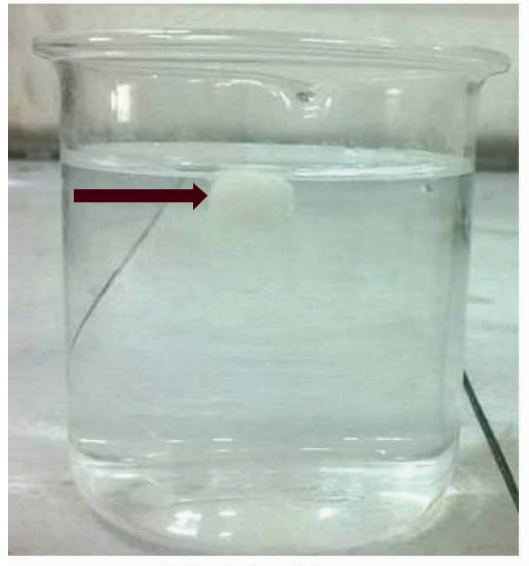

(D) After 2 hrs

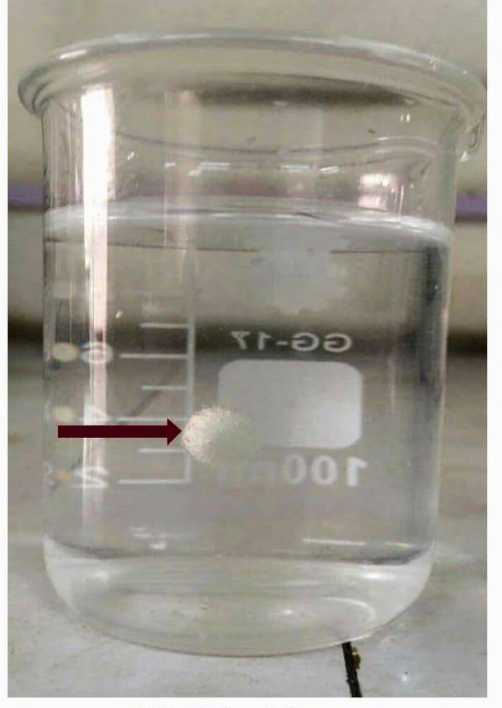

(B) After $30 \mathrm{sec}$

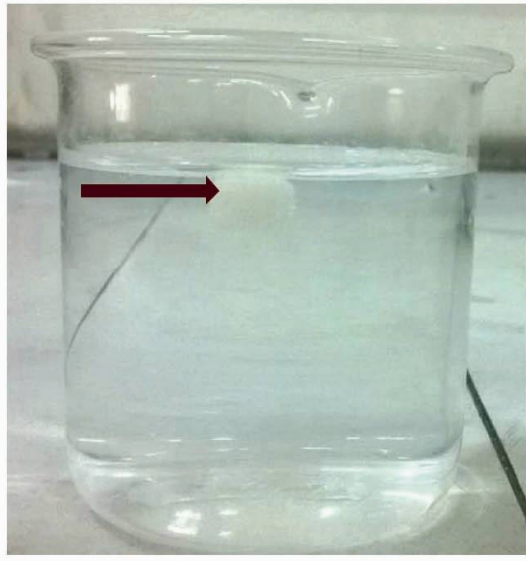

(E) After 4 hrs

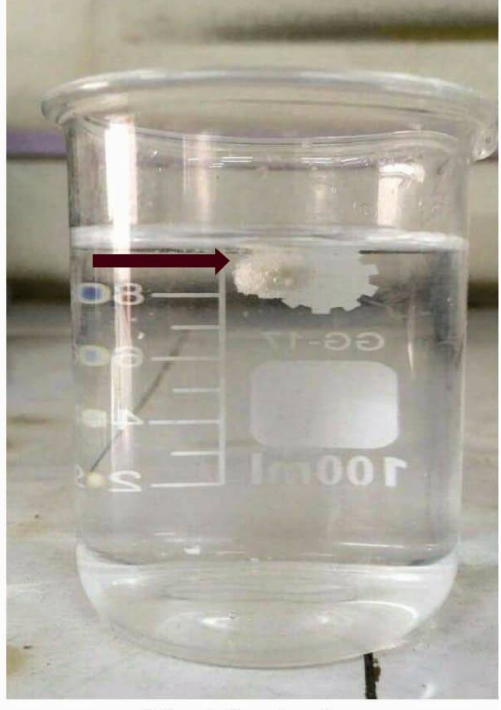

(C) After $1 \mathrm{~min}$

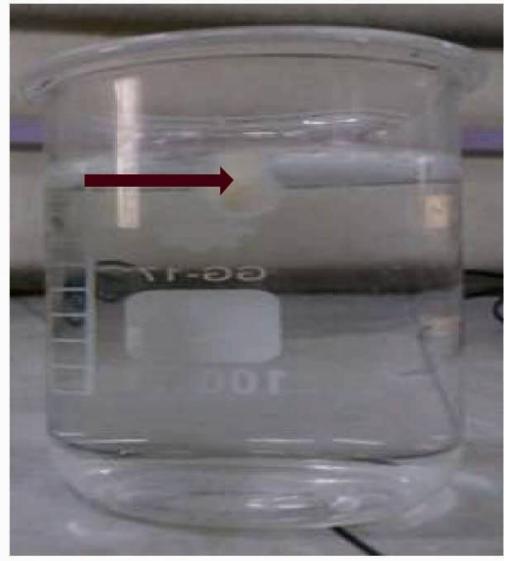

(F) After $12 \mathrm{hrs}$

Figure 1. Buoyancy time of gastroretentive floating tablets of domperidone at different time period. 
Table 3. Buoyancy study.

\begin{tabular}{ccc}
\hline $\begin{array}{c}\text { Formulation } \\
\text { no. }\end{array}$ & $\begin{array}{c}\text { Floating lag } \\
\text { time }(\mathrm{sec})\end{array}$ & $\begin{array}{c}\text { Total floating } \\
\text { time (hrs) }\end{array}$ \\
\hline D-1 & 43 & $>12$ \\
D-2 & 32 & $>12$ \\
D-3 & 24 & $>12$ \\
D-4 & 54 & $>12$ \\
D-5 & 59 & $>12$ \\
D-6 & 61 & $>12$ \\
\hline
\end{tabular}
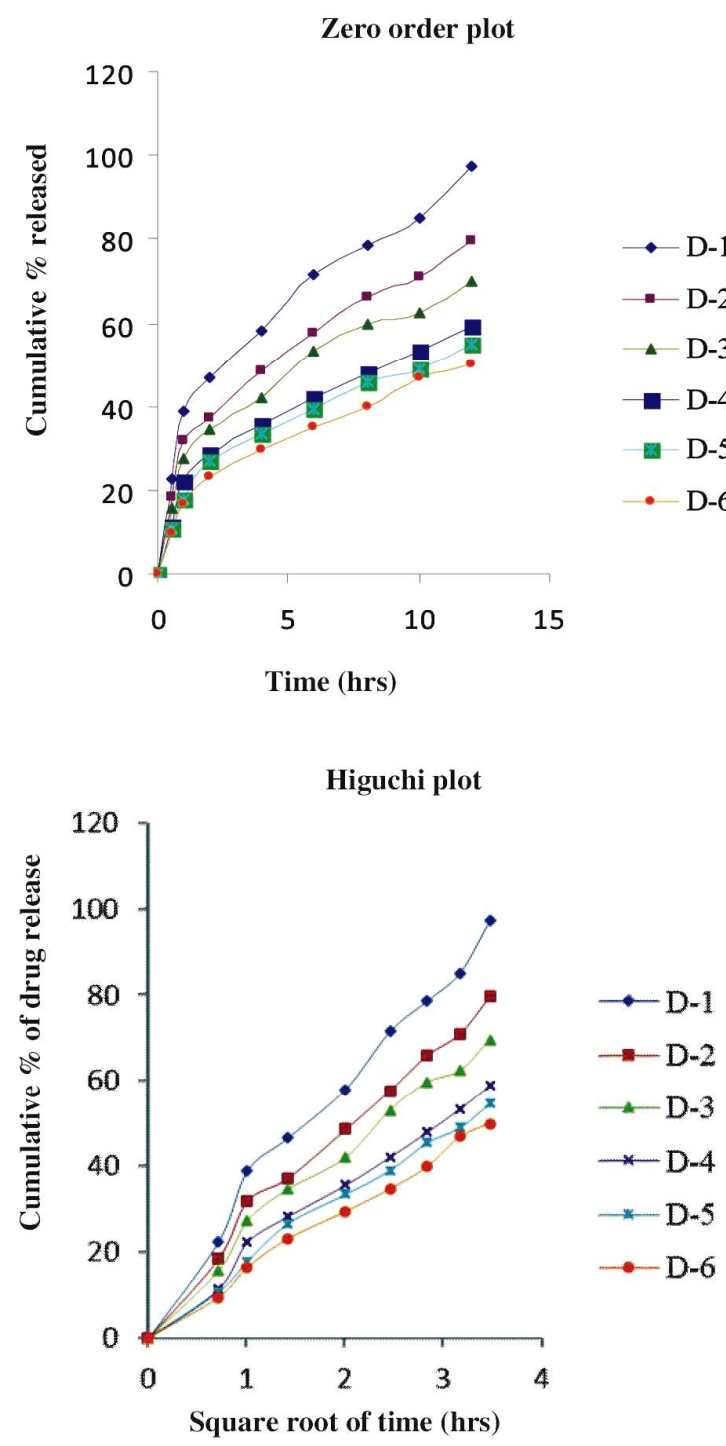

Compatibility study: FTIR spectrum of domperidone, Methocel K15M, Methocel K100M and the physical mixture of domperidone and polymers are given in figure 3. Figure 3 assured presence of all identical peaks in case of domperidone and the physical mixture indicating good compatibility of drug with polymers.
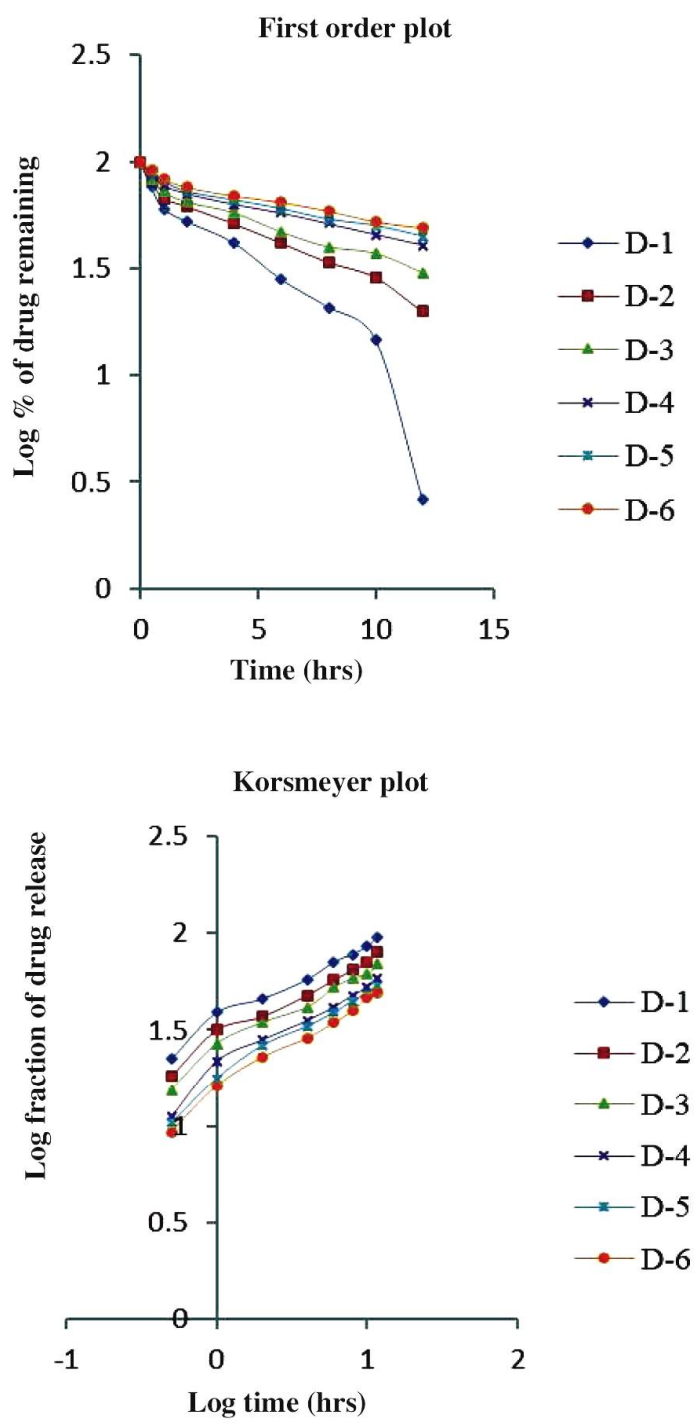

Figure 2. Different release patterns of formulations (D1-D6). 


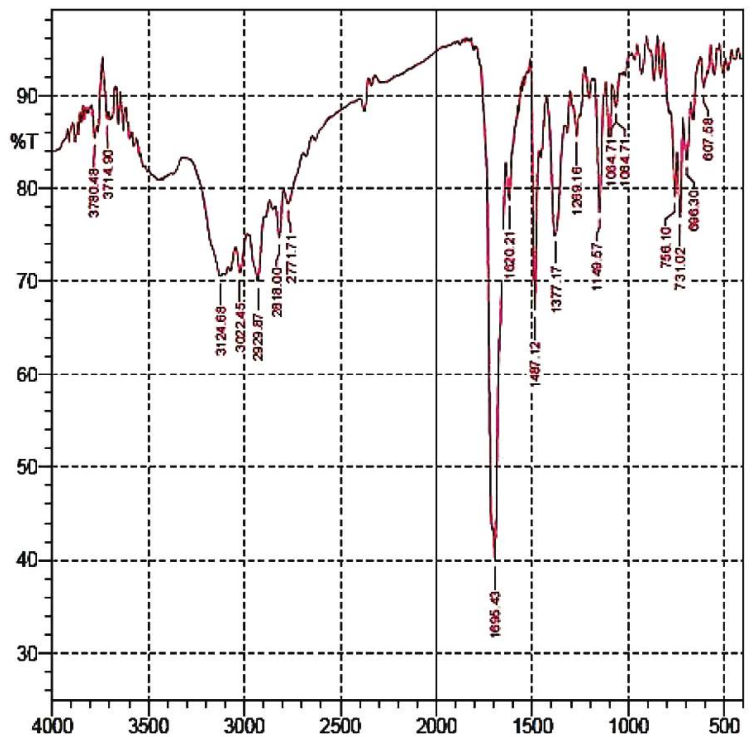

(A)

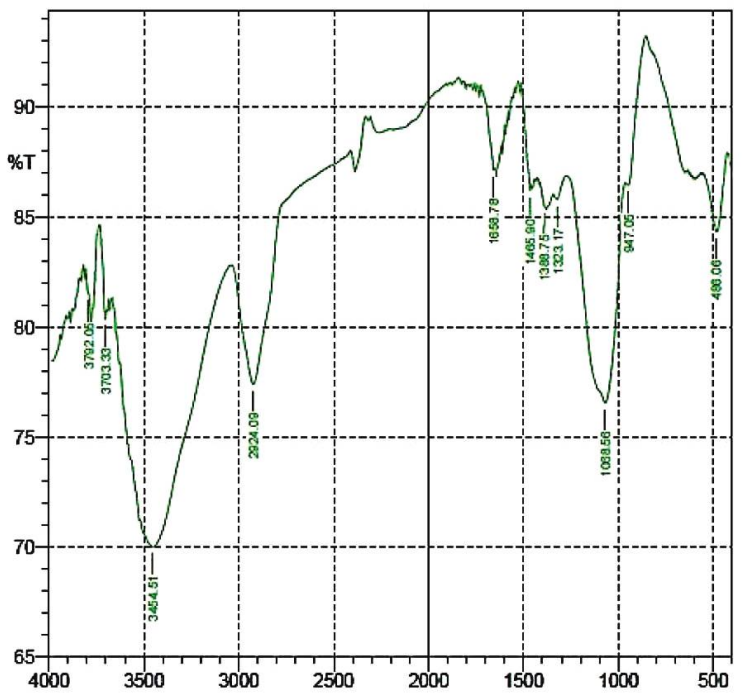

(C)

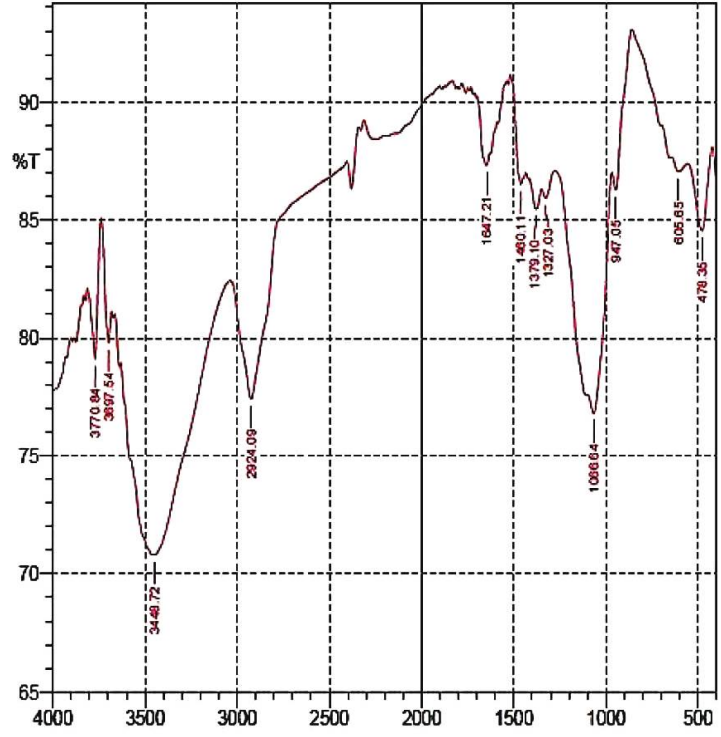

(B)

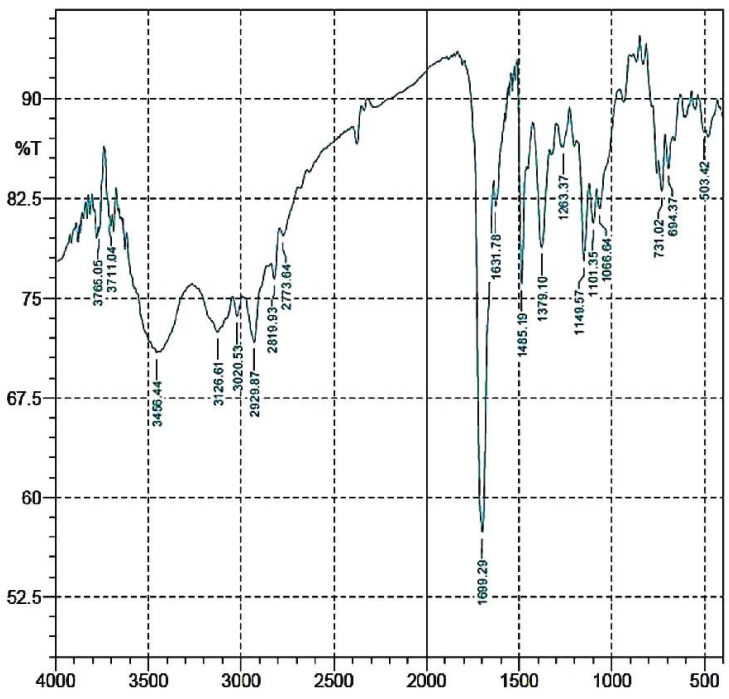

(D)

Figure 3. FTIR spectrum of (A) Domperidone (B) Methocel K15M (C) Methocel K100M (D) Physical mixture of drug and polymers.

\section{Conclusion}

Gastroretentive floating tablets of domperidone with acceptable properties were successfully prepared. Floating lag time was decreased when the amount of methocel KISM was increased but the lag time enhanced while the amount of methocell $\mathrm{K} 100 \mathrm{M}$ was increased. However, gastroretentive floating tablets of domperidone will ultimately increase the bioavailability of domperidon by means of higher residence time in the stomach.

\section{Acknowledgement}

This work was funded by University Grants Commission of Bangladesh. 


\section{References}

Albright, L.M. 2005. Use of domperidone as a prokinetic and antiemetic, Health and Wellness. Int. J. Pharm. Compounding. 9, 120-125.

Hoffman, A. 1998. Pharmacodynamic aspects of sustained release preparations. Adv. Drug Deliv. Rev. 33, 185-99.

Hoffman, A. and Stepensky, D. 1999. Pharmacodynamic aspects of modes of drug administration for optimization of drug therapy. Crit. Rev. Ther. Drug Carrier Syst. 16, 571-639.

Hwang, S.J., Park, H. and Park, K. 1998. Gastric retentive drug delivery systems. Crit. Rev. Ther. Drug Carrier Syst. 15, 243-84.

Khan, F., Razzak, M.S.M.I., Khan, Z.R., Azad, M.A.K., Chowdhury, J.A. and Reza, M.S. 2009. Theophylline loaded gastroretentive floating tablets based on hydrophilic polymers: preparation and in vitro evaluation. Pak. J. Pharm. Sci. 22, 155-161.

Moes, A.J. 1993. Gastroretentive dosage forms. Crit. Rev. Ther. Drug Carrier Syst. 10, 143-195.
Mamjek, R.C. and Moyer, E.S. 1980. Drug-dispensing device and method. US Patent, 4, 207, 890.

Reynolds, J.E.F.M. 1996. The Extra Pharmacopoeia. 31st eds. Pharmaceutical Press, London, pp. 1217-1218.

Rubinstein, A. and Friend, D.R. 1994. In: Polymeric SiteSpecific Pharmacotherapy (Domb, A.J., Eds.), Wiley, Chichester, pp. 267-313.

Sheth, P.R and Tossounian, J.L. 1979. Sustained release tablet formulations. US Patent, 4140755.

Singh, B.N. and Kim, K.H. 2000. Floating drug delivery systems: an approach to oral controlled drug delivery via gastric retention. J. Control. Rel. 63, 235-259.

Thomma, K. and Zimmer, T. 1990. Retardation of weakly basic drug with diffusion tablet. Int. J. Pharm. 58, 197-202.

Saha, T., Masum, U. and Ashrafi, S. 2018. Preparation and in-vitro evaluation of sodium alginate based gastroretentive floating tablet of domperidone. Galore Int. J. Health Sci. Res. 3, 1-4. 